\title{
Effect of Diatomite on the Accumulation of Lead and Cadmium in the Body of White Rats
}

\author{
Vasily I. Dorozhkin, Natalia A. Brichko, Natalia S. Pavlova* and Galina I. Pavlenko
}

All-Russian Research Institute of Veterinary Sanitation, Hygiene, and Ecology - a branch of the Federal State Budgetary Scientific Institution "Federal Scientific Center - All-Russian Research Institute of Experimental Veterinary Medicine named after K.I. Scriabin and Ya.R. Kovalenko Russian Academy of Sciences", Moscow, 123022, Russia

\begin{abstract}
Every year, pollution by eco-toxicants of natural and anthropogenic origin is becoming more and more acute. Some of the most toxic among them are heavy metals, especially cadmium and lead. These elements do not decompose. Once released into the environment, these elements continue to circulate in water, soil, and air for a very long time, accumulating in plants and livestock products. Therefore, there is a problem of obtaining safe agricultural products in areas contaminated with heavy metals. In animal husbandry, synthetic and natural enterosorbents are used for obtaining safe products. For example, such enterosorbents are shungites, bentonites, diatomites, clays. We tested diatomite from the Kamyshlovskoye deposit at a dose of $5.0 \mathrm{~g} / \mathrm{kg}$ of feed to reduce cadmium accumulation and lead during their combined intake. We investigated the feed intake of a combination of cadmium and lead at doses of 5.0 and $50.0 \mathrm{mg} / \mathrm{kg}$ feed. The result of this experiment is the accumulation of metals in the liver, kidneys, and bones, and, in addition, in the testes. The use of diatomite to reduce the accumulation of heavy metals has not been successful. There is an increase in lead accumulation in the liver, kidneys, and testes. The content of cadmium in diatomite is $3.86 \pm 0.20 \mathrm{mg} / \mathrm{kg}$, lead $-105.0 \pm 7.2 \mathrm{mg} / \mathrm{kg}$. The results obtained indicate that diatomite as a feed additive to reduce lead and cadmium intoxication did not show protective properties.
\end{abstract}

\section{Introduction}

Today, protecting the environment from the effects of various kinds of negative factors, including combined ones, is the most acute problem. This problem results from scientific and technological progress, the growth of industrial production, and the increasing intensity of the use of resources. As a result of human economic activity in the environment, pollutants are constantly increasing [1].

Heavy metals are currently one of the leading environmental pollutants. For example, cadmium and lead are classified as highly hazardous elements. The problem of heavy metal poisoning has a significant history, while its relevance is only increasing. Increasing emissions lead to the formation of zones of anthropogenic origin with anomalous content of heavy metals. These processes negatively affect agricultural production, namely, affect the health and productivity of farm animals, the safety of the resulting agricultural products, negatively affect human health $[2,3]$.

Depending on the degree of accumulation, ecotoxicants can cause environmental stress or an environmental crisis, disrupting the entire production cycle of environmentally friendly products. The initial element of this chain is manufactured human activity, then the soil, which accumulates ecotoxicants. Then they can migrate to plants (forage, agricultural products). Then heavy metals enter the body of animals and, ultimately, they accumulate in livestock products. Chronic intake of heavy metals into the body of animals is initially imperceptible. However, over time, the effect accumulates, and the health status of animals deteriorates, productivity and reproduction decrease [1-3].

The individual toxicity of lead and cadmium is well understood. They are metabolic poisons that block various enzyme processes by interacting with $\mathrm{SH}$-groups of proteins. In the course of evolution, mechanisms have been developed to prevent the toxic effect of heavy metals. However, they can no longer reliably protect living organisms [3, 4].

The target organs for lead poisoning are the hematopoietic and nervous systems and the kidneys. Anemia is observed due to increased hemolysis; damage to the brain and peripheral nerves is noted at the level of the nervous system. In chronic cadmium poisoning, the urinary and reproductive systems are affected, anemia develops, a decrease in iron absorption in the intestine and lysis of erythrocytes, osteoplastic and osteoporotic changes in bone tissue noted [4]. Lead and cadmium drastically reduce the productivity, reproduction, and resistance of farm animals to diseases. The accumulation

\footnotetext{
* Corresponding author: ns2008p@ mail.ru
} 
of heavy metals in livestock products deteriorates its quality and makes it dangerous for humans [2, 4].

Most often, combined poisoning with heavy metals occurs. Therefore, it is important to study the mechanisms and patterns of combined action to find effective and safe detoxifying and biologically active substances that have a protective and corrective effect on the body. The toxic effect is often caused by the sum of toxicants' effects and their interaction $[3,4]$.

Heavy metals are not capable of such transformations, unlike organic compounds, which are subject to some degree of decomposition and biotransformation. They are only redistributed between individual components of the ecosystem and can maintain their toxicity indefinitely $[3,5]$.

Pollution of heavy metals in soil, water, the air becomes the reason for their accumulation in food and feed, often in quantities exceeding the norm. Ensuring food safety is one of the priority areas of the state policy of the Russian Federation. Therefore, there is an acute issue of reducing the impact and accumulation of heavy metals in modern animal husbandry. For this purpose, enterosorption is most often used - a method based on the ability of sorbents to bind and remove various exogenous substances, microorganisms, and toxins from the body. The experiments show that the introduction of such sorbents as zeolites, bentonites, shungites, and others into the diet has a positive effect on the organism of animals and poultry as a whole and their productivity $[6,7]$.

Diatomite is a natural form of silicon dioxide formed from the remains of the shells of microscopic diatoms. Diatomite has a huge inner surface. This material has mainly a macroporous structure, pores with a radius of 4-40 $\mu \mathrm{m}$ makeup only $15 \%$ of the total pore volume, and its bulk density is $\approx 30 \mathrm{~g} / \mathrm{dm}^{3}$. Diatomite belongs to sedimentary rocks of organic origin. Diatomites contain a large number of mineral elements and have high ionexchange properties. At present, extensive material has been accumulated that in the body of animals, they can, under certain conditions, be donors or acceptors of certain mineral substances and through them influence the nature of biochemical processes.

Diatomites are almost entirely composed of amorphous silica. Diatomites contain calcium and iron oxides. In small quantities, there are copper chelates, oxides of magnesium, zinc, manganese [8-10].

Recently, diatomite (diatomaceous earth) has been used in various fields of industry and agriculture. So diatomite is widely used as an additive to the main feed [11-12].

Pharmacological agents and feed additives containing silicon compounds are more and more actively used due to their physiological activity; they have very good sorption properties. These properties make it possible to use them as a detoxifying agent and as a carrier for the active substances of premixes [6, 13].

The effect of natural sorbents in the body of animals is made up of complex biochemical processes. They enrich the body with biogenic macro-and microelements, adsorb and remove metabolic products and toxic substances, and increase the liver's detoxification function, providing the restructuring of protein, fat, and carbohydrate metabolism in animals and energy homeostasis [11-14].

It has been experimentally substantiated and proven that using the optimal dose of diatomite increases the usefulness of animal feeding. Natural sorbents improve the morphological and biochemical parameters of blood; internal organs' structural and functional state positively affects the digestibility and use of nutrients in feed, reproductive function, increases the quality of products and the profitability of its production [11-14].

This study aims to study the accumulation and distribution of lead and cadmium in the body of white rats after introducing diatomite into the feed against the background of cadmium and lead poisoning in laboratory conditions.

\section{Materials and methods}

Experimental studies were carried out in the vivarium of the All-Russian Research Institute of Veterinary Sanitation, Hygiene and Ecology-branch of the FGBNU Federal Scientific Center - All-Russian Research Institute of Experimental Veterinary Medicine of the Russian Academy of Sciences on outbred white male rats weighing 215-230 g. A sample of the marked diatomite from the Kamyshlovskoe deposit (gray powder) was used. We were guided by the moral and ethical standards of humane treatment of laboratory animals during the experiments.

The animals were divided into 3 groups:

1. the first group received cadmium nitrate and lead acetate (Reakhim) with food in doses, in terms of pure metal, 5.0 and $50.0 \mathrm{mg} / \mathrm{kg}$ (respectively);

2 . the second group received food with cadmium and lead salts at the same doses and diatomaceous earth at a therapeutic dose of $5.0 \mathrm{~g} / \mathrm{kg}$ of food;

3 . the third group is the control, where the animals received the usual food (Table 1).

Two months later, the animals were sacrificed, and samples of the liver, heart, kidneys, spleen, testes, femur, and muscles were taken from the thigh.

Table 1. Scheme of the experiment

\begin{tabular}{|c|c|c|c|}
\hline Group & $\mathbf{1}$ & $\mathbf{2}$ & $\mathbf{3}$ \\
\hline Name & $\mathrm{Cd}+\mathrm{Pb}$ & $\begin{array}{c}\mathrm{Cd}+\mathrm{Pb} \\
+ \\
\text { Diatomite }\end{array}$ & Control \\
\hline $\begin{array}{c}\text { Cadmium (cadmium } \\
\text { nitrate), } \mathrm{mg} / \mathrm{kg} \text { feed }\end{array}$ & 5.0 & 5.0 & 0 \\
\hline $\begin{array}{c}\text { Lead (lead acetate), } \\
\mathrm{mg} / \mathrm{kg} \text { feed }\end{array}$ & 50.0 & 50.0 & 0 \\
\hline Diatomite, g/kg feed & 0 & 5.0 & 0 \\
\hline
\end{tabular}

Determination of cadmium and lead content in animal tissues is based on an atomic absorption spectrophotometer Varian AA 240 FS (USA). The method is based on spraying a saline solution in an airacetylene flame and measuring the resonant absorption of atoms of the element being determined. In addition, the samples were subjected to hot acid mineralization on a Multiwave Go microwave sample preparation system 
(Austria). Reagents: concentrated nitric acid (analytical grade, GOST 4461-77), standard samples GSO 78742000 and GSO 7877-2000 (OOO "Ekroshim").

Atomic absorption determination was carried out under the following conditions: cadmium - reasonant wavelength - $228.8 \mathrm{~nm}$, spectral bandwidth of the monochromator - $0.5 \mathrm{~nm}$, hollow cathode lamp, atomization temperature $-2100{ }^{\circ} \mathrm{C}$; lead - resonant wavelength $217.0 \mathrm{~nm}$, the spectral bandwidth of the monochromator $-0.4 \mathrm{~nm}$, atomization temperature $2200{ }^{\circ} \mathrm{C}$ [15].

Statistical processing of the results was carried out according to the Student's method modified by Tippet [16] in Excel 2010.

\section{Results and Discussion}

At the end of the experiment, organ samples were taken from the animals. We have determined the content of cadmium and lead in the samples. Table 2 presents the results of the determination of cadmium in animal organs.

Table 2. Content of cadmium in organs of white rats, $\mathrm{mg} / \mathrm{kg}$

\begin{tabular}{|c|c|c|c|}
\hline Group & Control & $\mathrm{Cd}+\mathrm{Pb}$ & $\begin{array}{c}\mathrm{Cd}+\mathrm{Pb} \\
+ \text { Diatomite }\end{array}$ \\
\hline Liver & $0.48 \pm 0.10$ & $0.89 \pm 0.07 *$ & $0.95 \pm 0.09 *$ \\
\hline Kidneys & $0.47 \pm 0.09$ & $2.25 \pm 0.11^{*}$ & $2.40 \pm 0.34 *$ \\
\hline Heart & $0.64 \pm 0.14$ & $0.70 \pm 0.11$ & $0.71 \pm 0.04$ \\
\hline Spleen & $0.65 \pm 0.07$ & $0.85 \pm 0.10$ & $0.82 \pm 0.03$ \\
\hline Muscles & $0.59 \pm 0.06$ & $0.74 \pm 0.06$ & $0.64 \pm 0.02$ \\
\hline Bones & $1.20 \pm 0.07$ & $1.61 \pm 0.18^{*}$ & $1.27 \pm 0.07 * *$ \\
\hline Testis & $0.51 \pm 0.12$ & $0.67 \pm 0.11$ & $0.68 \pm 0.10$ \\
\hline
\end{tabular}

The data obtained indicate a significant accumulation of cadmium in the body of animals when it is supplied with feed. As follows from the table, the accumulation of cadmium in the liver, kidneys, and bones is significantly higher than the element's content in the organs of control animals. The highest cadmium content is observed in the kidneys, where it's almost fivefold increase in comparison with the control group is noted - from 0.47 to $2.25 \mathrm{mg} / \mathrm{kg}$. Significant accumulation of cadmium is in the liver: twice as much as in control $-0.89 \mathrm{mg} / \mathrm{kg}$ at 0.48 in control. To a lesser extent, cadmium accumulates in bones $-1.61 \mathrm{mg} / \mathrm{kg}$ at $1.20 \mathrm{in}$ control. The introduction of diatomite into animal feed did not significantly change the cadmium content in the studied tissues. Only a decrease in cadmium accumulation in bones was noted; the difference from the control became insignificant.

Table 3 presents data on the accumulation of lead in animal organs.

The data obtained showed that in case of poisoning with a combination of lead and cadmium, the most significant accumulation of lead (at $\mathrm{P}<0.05$ ), as well as cadmium, is observed in the kidneys (16.24 at $8.42 \mathrm{mg} / \mathrm{kg}$ in control), liver (15.26 at $8.95 \mathrm{mg} / \mathrm{kg}$ in control) and bones (34.03 at $22.10 \mathrm{mg} / \mathrm{kg}$ in control). In addition, if the accumulation of cadmium in the testes had the status of an upward trend, then the accumulation of lead in the testes was statistically higher (14.67) compared to the control (9.67).

Table 3. Lead content in the organs of white rats, $\mathrm{mg} / \mathrm{kg}$

\begin{tabular}{|c|c|c|c|}
\hline Group & Control & $\mathbf{C d}+\mathbf{P b}$ & $\begin{array}{c}\mathbf{C d}+\mathbf{P b} \\
+ \text { Diatomite }\end{array}$ \\
\hline Liver & $8.95 \pm 0.56$ & $15.26 \pm 1.43^{*}$ & $19.27 \pm 1.24^{*}$ \\
\hline Kidneys & $8.42 \pm 0.11$ & $16.24 \pm 2.20^{*}$ & $19.22 \pm 2.40^{*}$ \\
\hline Heart & $17.33 \pm 2.39$ & $14.93 \pm 3.11$ & $21.40 \pm 4.10$ \\
\hline Spleen & $11.86 \pm 1.38$ & $14.34 \pm 2.70$ & $16.24 \pm 2.79$ \\
\hline Muscles & $10.92 \pm 2.20$ & $14.64 \pm 2.08$ & $12.37 \pm 2.87$ \\
\hline Bones & $22.10 \pm 0.95$ & $34.03 \pm 5.00^{*}$ & $28.52 \pm 2.90^{*}$ \\
\hline Testis & $9.67 \pm 1.10$ & $\begin{array}{c}14.67 \pm 0.87^{*} \\
n=2\end{array}$ & $21.85 \pm 3.57^{*}$ \\
& & \multicolumn{3}{|l}{} \\
*) P<0,05 compared to control
\end{tabular}

Diatomite did not reliably reduce lead accumulation in any of the affected organs (only a downward trend was noted for bones). On the contrary, in the liver, kidneys, and testes, its content was even higher (19.27; 19.22 and $21.85 \mathrm{mg} / \mathrm{kg}$, respectively) than in the organs of rats that received only the combination of heavy metals.

In addition, we have previously established that the use of diatomite as an enterosorbent for lead and cadmium poisoning did not lead to the normalization of the studied indicators of the state of the body of white rats. The body weight remained significantly lower than the control, the content of immunoglobulin and $\mathrm{SH}$ groups in the blood serum and the amount of protein in the urine were also reduced. There was a significant increase in the summation threshold indicator, which indicates a decrease in neuromuscular excitability under the influence of heavy metals. Also, there was a significant increase in the weight coefficients of the liver and kidneys [17]. These data indicate the absence of a protective effect of this agent when it is added to feed as an enterosorbent for cadmium and lead poisoning.

Thus, diatomite did not show protective properties in chronic poisoning with a combination of lead and cadmium. Moreover, diatomaceous earth stimulated the accumulation of metals in some organs of animals.

Natural mineral sorbents (zeolites, bentonite clays, shungites, diatomites, and other sorbents) have a complex chemical composition, including several dozen elements, including phosphorus, potassium, calcium, iron, copper, manganese, cobalt, molybdenum, and other elements. In addition, natural sorbents contain toxic elements that have a different composition depending on their origin. The most common of these are cadmium, lead, arsenic, and mercury. So, when Shivyrtuin is included in the diet, lead is absorbed as much as possible - up to $5 \%$ of its mass fraction in the mineral, cadmium, fluorine, and arsenic - up to $20 \%$, mercury no more than $60 \%$. [18].

The entry into the body of toxic elements with sorbents and their subsequent desorption in the gastrointestinal tract can be one reason for the toxicity of Shivyrtuin (cytotoxic, mutagenic, and hemolytic activity, carcinogenic properties). The possibility of accumulation of toxic effects (mutagenic, carcinogenic, dystrophic 
changes in internal organs) in animals' bodies with the intragastric intake of zeolites has been revealed [19, 20].

Sapropels are natural geoorganic bottom sediments capable of accumulating pollutants (metals, oil products, pesticides), becoming secondary pollution sources [21].

The data obtained by us and in the literature were the basis for determining the content of lead and cadmium in diatomite. The cadmium content was $3.86 \pm 0.20 \mathrm{mg} / \mathrm{kg}$, lead $-105.0 \pm 7.2 \mathrm{mg} / \mathrm{kg}$. This data significantly exceeds the maximum allowable concentration for mineral additives [22]. Possibly, the high content of lead and cadmium in diatomite can be associated with the significant sorption capacity of diatomite, which accumulates heavy metals in a region unfavorable in terms of their content [23]. However, the sorption capacity of diatomite for cadmium and lead is more than $70 \%$, and when treated with $1 \mathrm{M}$ hydrochloric acid solution, 20-30 \% of adsorbed cadmium and lead are desorbed [24]. Based on these data, it is possible to assume the possibility of desorption of cadmium and lead contained in diatomite in the gastrointestinal tract of animals.

The issue is the advisability of diatomite using as a sorbent and a detoxifier for farm animals. At the very least, the content of heavy metals in it should be strictly controlled before use. It should be considered that, under certain conditions, instead of absorbing ecotoxicants by it, the opposite effect can be obtained, which is found, for example, when using diatomite for filtering alcoholic beverages [25].

\section{Conclusion}

Thus, in animals fed with a combination of cadmium $(5.0 \mathrm{mg} / \mathrm{kg}$ of food) and lead $(50.0 \mathrm{mg} / \mathrm{kg}$ of food $)$, the maximum accumulation of cadmium and lead in the kidneys, liver, and bones; lead to the same organs and in the testes was observed.

The addition of diatomite to the feed at a $5.0 \mathrm{~g} / \mathrm{kg}$ dose did not reduce the accumulation of lead and cadmium in the studied organs. In contrast, the accumulation of lead in the liver, kidneys, and testes tended to increase. The reason for this may be the high levels of lead and cadmium in diatomite and its desorption in the acidic environment of the stomach.

The results obtained indicate that diatomite as a feed additive to reduce lead and cadmium intoxication did not show any protective properties. Further study of the mechanisms of interaction of heavy metals with diatomite and the influence of various factors on its sorption capacity and composition is required.

\section{References}

1. C. Li, K. Zhou, W. Qin, C. Tian, M. Qi, X. Yan, X. Yan, W.A. Han, Techn. Soil \& sedim. Contaminat., 28(4), 380 (2019)

2. C. Ciobanu, B.G. Slencu, R. Cuciureanu, Rev. Med. Chir. Soc. Med. Nat. Iasi., 116(2), 617 (2012)
3. T.I. Bokova, Ecological Foundations of Innovative Improvement of Food Products (Publ. House of NSAU, Novosibirsk, 2011)

4. A.M. Malov, V.K. Sibiryakov, R.K. Glushkov, Bull. of the Russ. Military Med. Acad., 36(2(S1)), 55 (2017)

5. N.O. Babieva, O.L. Glavati, Ecotechnol. and res. Conser., 6, 38 (2011)

6. E.V. Arhitskaya, I.V. Yakushkin, Electr. Sci. and methodol. J. of Omsk State Agrar. Univ., Special issue, 2 (2016)

7. F.I. Idiatullin, Natural mineral resources in the system of optimizing animal nutrition and increasing their productivity in the Republic of Tatarstan (Doct. dissertation) (Ulyanovsk, 2002), $281 \mathrm{p}$.

8. N.N. Lantseva, K.Ya. Motovilov, Agricult. Sci., 3, 49 (1991)

9. M. Stavrov, V. Gridin, P. Agapov, Feed industry, 6, 31 (1994)

10. V.F. Gridin, Using diatomaceous earth as a base for premixes for dairy cows, In the coll. Experience and prospects of using local mineral resources in agriculture (1998), pp. 34-38

11. E.M. Ermolova, Improving the productive qualities of pigs when using natural mineral supplements in the diets of the Ural region (Doct. dissertation) (Troitsk, 2017)

12. O.S. Guseva, T.Ya. Dyuldina, A.Ya. Savinkov, A.P. Koschaev, M.P. Semenenko, Veter. Med. of Kuban, 5 (2018)

13. L.A. Mansurova, O.V. Fedchishin, V.V. Trofimov, T.G. Zelenina, L.Ye. Smolyanko, Sib. Med. J., 7, 16 (2009)

14. A.V. Savinkov, O.S. Guseva, T.V. Mikhaleva, The effect of diatomite and biooretron preparations on the activity of biochemical factors characterizing the liver metabolism of piglets, Mat. of the regional sci. and pract. Interdepart. Conf. Actual problems of veterinary medicine, medicine and biotechnology in modern conditions and ways to solve them (2015) pp. 249-252

15. V.V. Ustenko (Devel.), Determination of lead content in organs and tissues of animals by atomic absorption spectrometry, Method. directions (VASKHNIL, Moscow, 1980), 7 p.

16. M.A. Belenky, Experiments to quantify the pharmacological effect (Leningrad, 1983), 71 p.

17. V.I. Dorozhkin, G.I. Pavlenko, N.S. Pavlova, D.A. Drozdov, N.A. Brichko, Russ. J. Probl. of Veter. Sanit., Hyg. and Ecol., 2(38) (2021) (to be published)

18. Yu.V. Pavlenko, Assimilation of toxic elements and calculation of their maximum permissible concentration in zeolite-containing rocks, Natural zeolites of Russia: Medical and biological properties and application in agriculture, Theses of conference reports, Vol. 2 (November, 25-27 1991) (Novosibirsk, 1992), pp. 17-23 
19. L.N. Pylev, I.E. Valamina, Bull. of oncol. sci. Center Ross. Acad. honey Sci., 6(1), 12 (1995)

20. V.N. Frash, N.N. Vanchugova, E.E. Rosenberg, L.G. Malysheva, A.S. Fomina, S.V. Shcherbakov, On the possibility of cumulation of toxic effects under experimental exposure to zeolites, Natural zeolites of Russia: Medical and biological properties and application in agriculture, Theses of conference reports, Vol. 2 (November 25-27, 1991) (Novosibirsk, 1992), pp. 12-14

21. D.S. Chukurov, Ya.V. Medvedeva, O.V. Nikitin, Russ. J. of Appl. Ecol., 1, 22 (2016)

22. Temporary maximum permissible level (ML) for the content of certain chemical elements and gossypol in feed for farm animals and feed additives (approved by the Main Directorate of Veterinary Medicine of the State Agroindustrial Committee of the USSR on August 7, 1987)

23. National Atlas of Russia (on behalf of the Government of the Russian Federation dated May 26, 2000, no. AG - P 9 - 14991), Vol. 2, 495 p. Retrieved from: https: //nationalatlas.rf/cd2/316/316.html

24. A.M. Maksatova, A.I. Vezentsev, M.O. Mikhailyukova, L.A. Kalashnikova, Bull. of modern res., 7-1(10), 162 (2017)

25. B.W. Redan, J.E. Jablonski, C. Halverson, J. Jaganathan, A. Mabud Md., L.S. Jackson, J. Agric. Food Chem., 67(9), 2670 (2019) 